\title{
AXIAL COMPRESSOR DETERIORATION CAUSED BY SALTWATER INGESTION
}

\author{
Elisabet Syverud \\ NTNU \\ Norwegian University of Science and Technology \\ Department of Energy and Process Engineering \\ N-7491 Trondheim, Norway
}

\author{
Olaf Brekke \\ Royal Norwegian Navy \\ Bergen, Norway
}

\author{
Lars E. Bakken \\ NTNU, Norwegian University of Science and Technology, \\ Department of Energy and Process Engineering, N-7491 Trondheim, Norway
}

\begin{abstract}
Gas turbine performance deterioration can be a major economic factor. An example is within offshore installations where a degradation of gas turbine performance can mean a reduction of oil and gas production.

This paper describes the test results from a series of accelerated deterioration tests on a GE J85-13 jet engine. The axial compressor was deteriorated by spraying atomized droplets of saltwater into the engine intake.

The paper also presents the overall engine performance deterioration as well as deteriorated stage characteristics. The results of laboratory analysis of the salt deposits are presented, providing insight into the increased surface roughness and the deposit thickness and distribution.

The test data show good agreement with published stage characteristics and give valuable information regarding stageby-stage performance deterioration.
\end{abstract}

Keywords: Axial compressor, salt, roughness, stage characteristics, GE J85-13

\section{INTRODUCTION}

Compressor fouling causes $70-85 \%$ of the performance loss due to deterioration in gas turbines [1]. The degradation rate will be affected by site-specific conditions of the fouling and by engine operating conditions. A thorough review of engine performance deterioration mechanisms and modeling is given by Kurz and Brun [2].
From operating experience and literature the first stages of an axial compressor are expected to be the ones most heavily fouled. Deposits will have different characteristics depending on the nature of the fouling. Dry particles in dry atmospheres are likely to deposit in different areas compared to sticky matters and oily compounds. At high inlet humidity, the drop in static pressure during acceleration will increase the dust adhesion on the blades $[3,4]$.

To understand and reveal the degradation and restoration mechanisms related to recoverable compressor deterioration a systematic test campaign has been performed on a GE J85-13 jet engine. The overall performance of the gas turbine, and compressor stage characteristics were analyzed in detail. The tests reflect actual performance deterioration as found in offshore applications and provide valuable information regarding overall and stage-by-stage compressor performance deterioration in a real engine.

The tests were part of a larger online water wash test program. The results from this program are reported by Syverud and Bakken [5], and that paper should be seen in context with the present work.

$\begin{array}{cl}\text { NOMENCLATURE } & \\ \mathrm{A} & \text { Effective flow area, }\left[\mathrm{m}^{2}\right] \\ \mathrm{c}_{\mathrm{p}} & \text { Specific heat at constant pressure }[\mathrm{kJ} / \mathrm{kgK}] \\ \mathrm{C} & \text { Absolute air velocity, }[\mathrm{m} / \mathrm{s}] \\ \mathrm{CIT} & \text { Compressor inlet temperature, }[\mathrm{K}] \\ \mathrm{CIP} & \text { Compressor inlet pressure, }[\mathrm{kPa}]\end{array}$




\begin{tabular}{|c|c|}
\hline GE & General Electric \\
\hline IGV & Inlet guide vanes \\
\hline ISO & Int. Organization for Standardization $\left({ }^{*}\right)$ \\
\hline $\mathrm{k}$ & Grain size of salt crystals, $[\mu \mathrm{m}]$ \\
\hline $\mathrm{k}_{\mathrm{s}}$ & Equivalent sand roughness, $[\mu \mathrm{m}]$ \\
\hline$\dot{\mathrm{m}}$ & Mass flow rate, $[\mathrm{kg} / \mathrm{s}]$ \\
\hline MW & Molecular weight $[\mathrm{kg} / \mathrm{kmole}]$ \\
\hline $\mathrm{N}$ & Shaft speed, [rpm] \\
\hline NACA & $\begin{array}{l}\text { National Advisory Committee for } \\
\text { Aeronautics }\end{array}$ \\
\hline NASA & $\begin{array}{l}\text { National Aeronautics and Space } \\
\text { Administration }\end{array}$ \\
\hline $\mathrm{P}$ & Pressure, $[\mathrm{kPa}]$ \\
\hline PS & Pressure side (concave) of blades/ vanes \\
\hline $\mathrm{R}$ & Gas constant, $[\mathrm{kJ} / \mathrm{kgK}]$ \\
\hline $\mathrm{R}_{0}$ & Universal gas constant, $[\mathrm{kJ} / \mathrm{kgK}]$ \\
\hline $\operatorname{Re}$ & Reynolds number \\
\hline R.H. & Relative humidity, [\%] \\
\hline RNoAF & Royal Norwegian Air Force \\
\hline RTD & Resistance temperature detector \\
\hline SS & Suction side (convex) of blades and vanes \\
\hline $\mathrm{T}$ & Temperature, $[\mathrm{K}]$ \\
\hline $\mathrm{U}$ & Blade velocity, $[\mathrm{m} / \mathrm{s}]$ \\
\hline $\mathrm{V}$ & Relative air velocity, $[\mathrm{m} / \mathrm{s}]$ \\
\hline war & Specific humidity, [ $\mathrm{kg} \mathrm{H}_{2} \mathrm{O} / \mathrm{kg}$ dry air] \\
\hline $\mathrm{x}$ & Molar fraction of component \\
\hline$\alpha$ & Absolute air angle, $[\mathrm{deg}]$ \\
\hline$\beta$ & Relative air angle, $[\mathrm{deg}]$ \\
\hline$\rho$ & Air density, $\left[\mathrm{kg} / \mathrm{m}^{3}\right]$ \\
\hline$\eta$ & Polytropic efficiency \\
\hline$v$ & Kinematic viscosity, $\left[\mathrm{m}^{2} / \mathrm{s}\right]$ \\
\hline$\gamma$ & Ratio of specific heats \\
\hline$\Psi^{\mathrm{T}}=\mathrm{c}_{\mathrm{p}} \Delta \mathrm{T}_{\mathrm{t}} / \mathrm{U}_{\text {tip }}^{2}$ & Stage work coefficient, $\left[(\mathrm{kJ} / \mathrm{kg}) /(\mathrm{m} / \mathrm{s})^{2}\right]$ \\
\hline$\Phi=\mathrm{C}_{\mathrm{a}} / \mathrm{U}_{\mathrm{tip}}{ }^{2}$ & Flow coefficient \\
\hline \multicolumn{2}{|l|}{ Subscripts } \\
\hline $\mathrm{a}$ & Axial velocity component \\
\hline amb & Ambient condition \\
\hline $\operatorname{mix}$ & Mixture (humid air) \\
\hline $\mathrm{s}$ & Static condition \\
\hline $\mathrm{t}$ & Total condition \\
\hline tip & Tip \\
\hline VMD & Volume median diameter \\
\hline $\mathrm{w}$ & Tangential velocity component \\
\hline $2.1,2.2, \ldots 2.7$ & Compressor stage $1,2, \ldots$ to stage 7 \\
\hline 3 & Compressor discharge \\
\hline 5 & Turbine discharge \\
\hline
\end{tabular}

\section{TEST FACILITIES AND ENGINE DESCRIPTION}

The General Electric (GE) J85-13 engine has been a successful engine in different applications since it first entered

* ISO reference conditions assume an ambient temperature of $288.15 \mathrm{~K}$, a barometric pressure of $101.325 \mathrm{kPa}$ and a relative humidity of $60 \%$. service in 1960. More than 6000 engines are still in service worldwide. The Royal Norwegian Air Force (RNoAF) F-5 Freedom Fighters have two GE J85-13 engines for propulsion. Because these aircrafts have been replaced by the F-16 aircraft, one GE J85-13 engine has been made available to the Norwegian University of Science and Technology (NTNU) for use in this project. Engine testing was carried out a the RNoAF's test facilities at Kjeller, Norway. Kjeller is located inland, $\sim 25 \mathrm{~km}$ east of Oslo at an altitude of $119 \mathrm{~m}$ above sea level.

The GE J85-13 is a compact, light-weight, single-spool turbojet engine. It has an eight-stage axial-flow compressor that is directly coupled to a two-stage turbine. The exhaust nozzle has a variable throat area, and the engine is equipped with an afterburner. The GE J85-13 is rated to deliver a minimum thrust of $2720 \mathrm{lbs}(12.1 \mathrm{kN})$ at $100 \%$ shaft speed without the afterburner and a minimum thrust of $4080 \mathrm{lbs}(18.1 \mathrm{kN})$ with full afterburner.

The eight-stage compressor has a pressure ratio of 6.5:1. First- and second-stage rotor blades are coated for corrosion protection. To handle off-design operation, the compressor has variable inlet guide vanes (IGV) and bleed-off-valves at stages $3-5$, as well as a variable exhaust nozzle. The variable geometry is controlled by the throttle angle, but the timing is ambient temperature biased. At ISO conditions, IGV will be at maximum deflection and bleed-off-valves will be fully open below $\sim 81 \%$ corrected speed and fully closed at $>96 \%$ corrected speed. At ambient temperatures above ISO conditions, the bleed-offvalves will close at lower speed settings. The nozzle is controlled by the throttle as long as the engine is running below the exhaust temperature limit. When the maximum exhaust temperature is reached, the exhaust nozzle will increase the flow. This reversal in the exhaust nozzle schedule occurs close to the maximum throttle angle.

Bleed air is also used for internal cooling of the afterburner actuators, combustor liner, and turbine guide vanes. Bleed air for anti-ice is taken at the compressor discharge. The anti-ice air valve was kept closed during all tests associated with this project.

\section{Engine model data}

Detailed knowledge of compressor stage geometry is available through several sources providing a good basis for developing engine simulation models.

NASA carried out several tests on the GE J85-13 in the late 1960 's and throughout the 1970's. Hager [6] analyzed internal flow of the GE J85-13 multiflow compressor and reported compressor stage temperature and pressure profiles. Milner and Wenzel [7] studied the effect on compressor performance from clean and distorted inlet flow, and their work includes individual compressor stage characteristics. Compressor characteristics are also given by Willoh and Seldner [8], whereas engine geometry is given by Tesch and Steenken [9]. 


\section{Initial engine condition}

The engine used in this test program was preserved and stored after serving $\sim 300$ hours onboard an aircraft. The engine was not overhauled prior to testing.

To avoid disturbances to the airflow attributable to loose coating, the coating on the second-stage rotor blades was removed by hand prior to the testing, using emery paper grade 320. The compressor inlet, inlet guide vanes, first-stage rotor, and stator were cleaned by hand using solvent, while the upper half of the casing, including stator vanes from stages 1-7 were cleaned using an ultrasonic cleaning bath. In addition, online compressor cleaning was performed prior to the testing using water at a flow of $13.2 \mathrm{l} / \mathrm{min}$, for a 30 second period at idle, 70, 90, 95 and $100 \%$ corrected engine speed. Details of the online water wash system are given by Syverud and Bakken [5].

\section{ENGINE INSTRUMENTATION}

Additional sensors were installed to provide more information than is available from standard, test-cell instrumentation. The engine instrumentation is shown in Fig. 1.

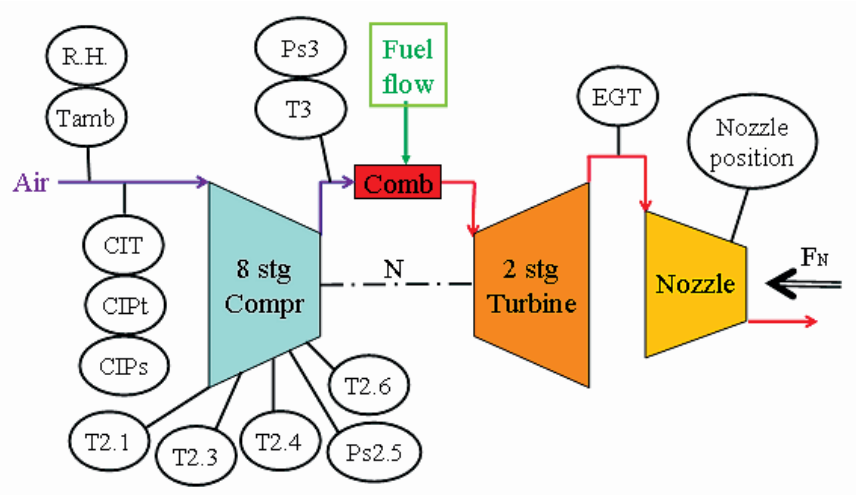

Figure 1 GE J85-13 engine instrumentation

The temperatures at stages $1,3,4,6$ and 8 were measured using a single resistance temperature detector (RTD) at each stator row. The entire $15 \mathrm{~mm}$ sensor length was immersed into the airflow, giving a representative measure of the bulk average temperature. Because the sensors are unshielded, the velocity error will be significant in the temperature reading. The velocity error was calculated as recommended in AGARD AR-245[10] with a recovery factor of 0.65 .

The static pressures at stage 5 and at compressor discharge were measured at a single point on the circumference. The stage 5 static pressure was measured in the bleed channel.

Engine throttle and nozzle position were recorded manually at each setting. Relative humidity and ambient temperature were recorded manually throughout the testing and measured at the same location outside of the test-cell intake. Due to test-cell recirculation, the recorded compressor inlet total temperature (CIT) was slightly higher than the measured ambient temperature. CIT was measured using four sensors located at the engine inlet screen.

All instruments were calibrated prior to the test program and the measurement uncertainties were calculated based on methods given in the ASME Performance Test Codes [11,12].

To reduce the data scatter, a minimum of 60 data points $(2 \mathrm{~Hz}$ sampling rate) were collected at each setting. The average of these readings was taken as the steady-state data point.

\section{ENGINE DEGRADATION METHOD AND EQUIPMENT}

Accelerated engine deterioration was done through the ingestion of atomized saltwater. A similar method has been used by the United States Navy [13]. The saltwater ingestion system is illustrated in Fig. 2. Saltwater was atomized in front of the compressor inlet using four atomizing nozzles installed on a bracket on the online water wash manifold positioned $0.77 \mathrm{~m}$ in front of the compressor inlet. This ensures complete atomization of the saltwater prior to the inlet guide vanes. The saltwater was gravity fed from a storage tank while air pressure was taken from the pressurized air supply in the test-cell.

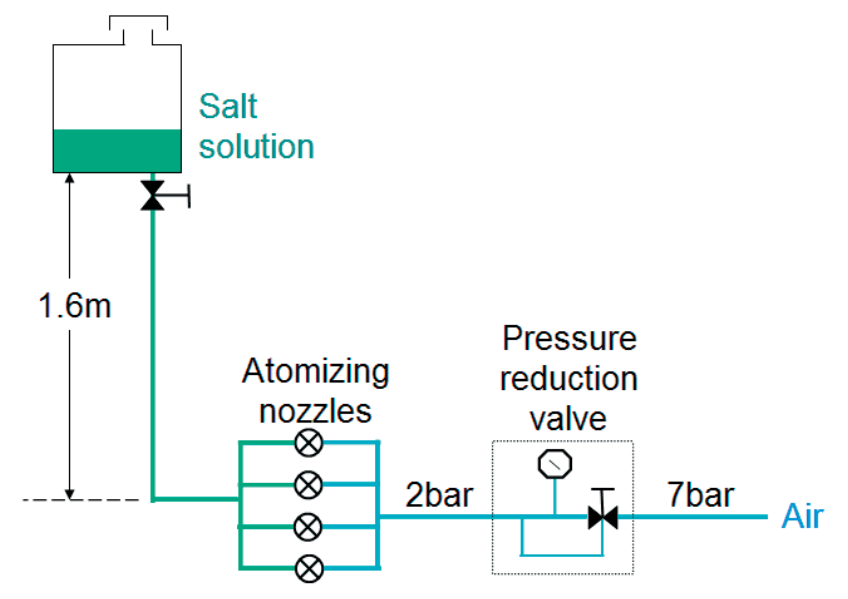

Figure 2 Salt ingestion system

The droplet diameter of the saltwater spray was measured as $23 \mu \mathrm{m}$ median volume diameter (VMD) in still air using a Malvern laser diffraction spray analyzer and applying the ASTM Standard E799-92 for calculating spray characteristics [14]. The measurements were taken at the center of the fully developed spray at a distance of $44 \mathrm{~cm}$ from the nozzles. The 23 $\mu \mathrm{m}$ VMD is higher than the $0-8 \mathrm{~mm}$ droplet size indicated as typical values after the intake filters of marine gas turbine units [15].

For all salt-deterioration tests, three liters of saltwater were ingested at a flow rate of $0.2 \mathrm{l} / \mathrm{min}$. The salt concentrations in the initial tests were 0.2 and $0.4 \%$ by weight. For the accelerated deterioration tests associated with the online water wash trials, three liters of saltwater was ingested with a salt concentration of $1 \%$ (by weight). The salt used in the tests constituted (by 
weight) $99.83 \%$ sodium chloride, $0.04 \%$ calcium, $0.03 \%$ magnesium and $0.1 \%$ sulphione.

\section{TEST PROCEDURE}

The engine baselines were established for steady-state operation at 12 operating points from $60 \%$ corrected speed to full load. Prior to establishing each baseline, the engine was run for 5 minutes at full load. Engine speed was then reduced to idle before being increased to the initial throttle setting. At each throttle setting, the engine was allowed to stabilize for 1 minute before reading 60 data points. To prevent impact of hysteresis from the instrument or control system, all throttle settings were established at increasing engine speeds. Engine baselines were recorded prior to degradation, after salt degradation, and after each online water wash.

All salt degradation trials were run at $10^{\circ}$ throttle angle (equivalent to $97.5 \%$ engine shaft speed) at constant nozzle position and with closed bleed-off-valves and fully open IGV.

To completely clean the compressor of salt deposits, a 5 minute online water wash was done at engine speeds varying from full speed to idle for two complete cycles using 17.6 liters of water per minute (droplet size of $200 \mu \mathrm{m}_{\mathrm{VMD}}$ ).

\section{SALT DEPOSITS}

The salt deposits on the axial compressor were analyzed non-destructively. Deposits on the stator vanes were analyzed at a laboratory. The deposits on the rotor blades were visually evaluated, because the rotor assembly could not be moved to the laboratory within the available timeframe.

\section{Location of deposits}

The salt deposits were mainly found along the leading edge of the first four stages and on the pressure side of the stator vanes along the hub. The heaviest deposits were found along the first-stage annulus, at the leading edge of the second-stage stator vanes and along the hub at the pressure side of the second-and third-stage blades and vanes.

Significantly less deposit were observed on the rotor blades compared to the stator vanes. The rotor blade deposits were mainly on stages 2-4. Deposits of a coarse structure were found along the hub, while deposits of a finer structure were found along the annulus. These deposits covered $35 \%$ of the second-stage pressure side and $20 \%$ of the third-stage pressure side.

For the fourth stage, the deposits were different from the previous stages, occurring as a shimmering layer covering the entire pressure side surface, except for the $20 \%$ closest to the hub. Suction-side deposits were virtually non-existing, except for some traces found along the separation line on the first- and second-stage blades. Leading-edge deposits were found on stages 2-4.

Only immeasurable traces of salt (streaks) were found on the suction side of the fifth- and sixth-stage stator vanes and along the leading edge of the fifth-stage rotor blades. The spanwise distance between the streaks varied from $0.11 \mathrm{~mm}$ on the fifth-stage suction side to $0.17 \mathrm{~mm}$ and $0.88 \mathrm{~mm}$ on the sixthstage suction and pressure sides, respectively. No salt deposits were found on the sixth-stage rotor or on stages seven and eight.

The salt deposits on the stator vanes at the top half of the compressor were measured by dissolving the salt in water and measuring conductivity and chloride content. The results correlated well. Chloride content was transformed to a distribution of the salt deposits on the stator vanes as shown in Fig.3.

In Fig.3, the data are compared to results of an investigation of compressor blade contamination carried out on the 16-stage compressor of the Nuevo Pignone MS5322R by Tarabrin, Schruvsky, Bodrov and Stalder [16]. The deposits are given as a percentage distribution to outbalance differences in the number of vanes measured. The salt deposits measured for the GE J85-13 include the deposits along the annulus; this is not the case for the data obtained by Tarabrin et al.

In the investigation by Tarabrin et al., the rotor and stator blades of the first stage had more deposits on the suction side. The deposited masses on the blades aft of the first stage were approximately equal for the two sides. More deposits were found on the stator blades than on the rotor blades. Tarabrin et al. suggest that this is due to a certain cleaning effect on rotor blades from the influence of centrifugal forces on the dirt particles. The findings of Tarabrin et al. correspond to the findings of this project, except that the salt deposits in the present study were mainly on the pressure side of the stator vanes.

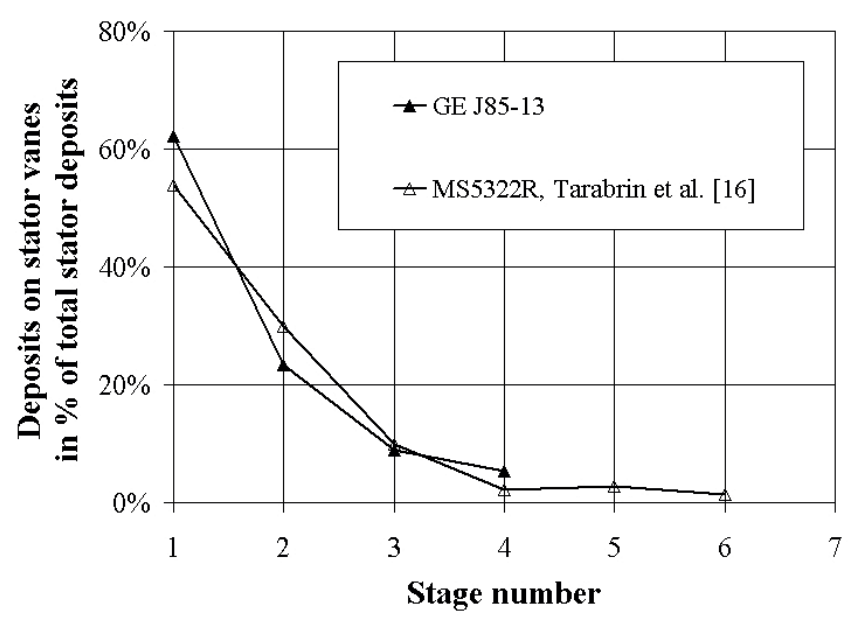

Figure 3 Percentage distribution of deposits on stator vanes

\section{Deposit thickness}

The salt deposits were analyzed using laboratory electron microscopes. Figure 4 shows the leading-edge deposits close to the hub on the second-stage stator vanes. The heavy leadingedge deposits are probably caused by the constant shaft speed 
during salt ingestion. Although the engine has been run at several speeds after salt deterioration, the buildup is strong enough to withstand the increased turbulence due to changing incidence at lower speed settings, since only parts of the deposits were broken off by the airflow. The leading-edge deposits were measured using the microscope and the results are given in Table 1.

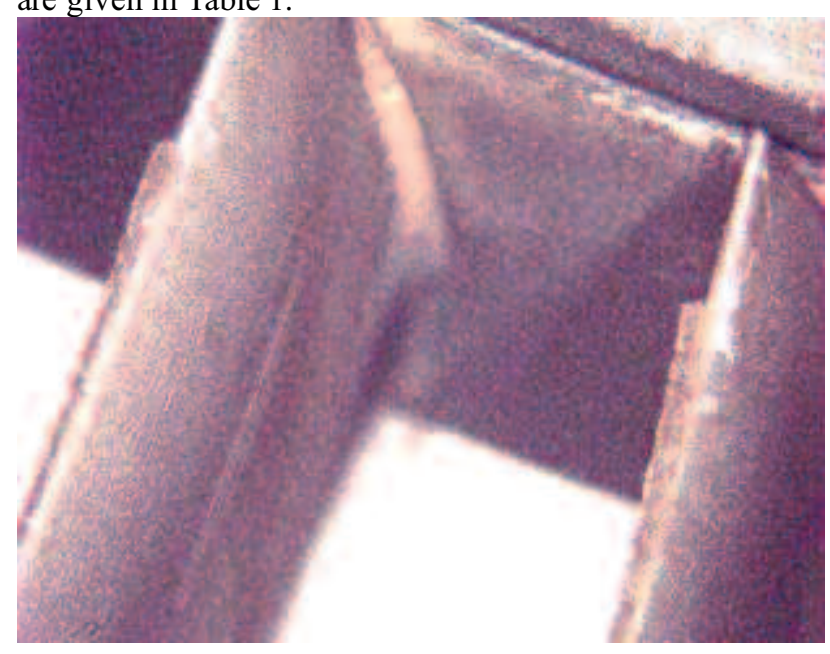

Figure 4 Salt deposits at the leading edge of the second-stage stator vanes (at 6.5x magnification). Hub is up in this image.

Table 1 Leading-edge deposit thickness

\begin{tabular}{|c|l|}
\hline Stator stage number & Leading-edge salt deposits \\
\hline 1 & No deposits at leading edge \\
\hline 2 & $500 \mu \mathrm{m}$ at hub, 25 $\mu \mathrm{m}$ at annulus \\
\hline 3 & $\begin{array}{l}200 \mu \mathrm{m} \text { at hub, no deposits ang } \\
\text { annulus }\end{array}$ \\
\hline 4 & $125 \mu \mathrm{m}$ at hub, 25 $\mu \mathrm{m}$ at annulus \\
\hline $5-8$ & No deposits \\
\hline
\end{tabular}

\section{Mean line salt crystal characteristics}

The grain size and surface structure of the salt crystals along the mean line of the first three stators were analyzed from Struers replicas. Struers replicas enable three-dimensional replicas of material microstructure with a resolution as low as 0.1 $\mu \mathrm{m}$ and pick up loose particles on the surface that can be further analyzed with a microscope [17].

Figure 5 shows the salt grains found on a $330 \times 240 \mu \mathrm{m}$ surface on the pressure side of the first-stage stator. In general, the suction side had smaller, more homogenous grain sizes. The salt crystals on the pressure side were larger and more distributed; for stages 2 and 3 they were caught in a thin film of liquid salt flowing in the direction of the air flow.

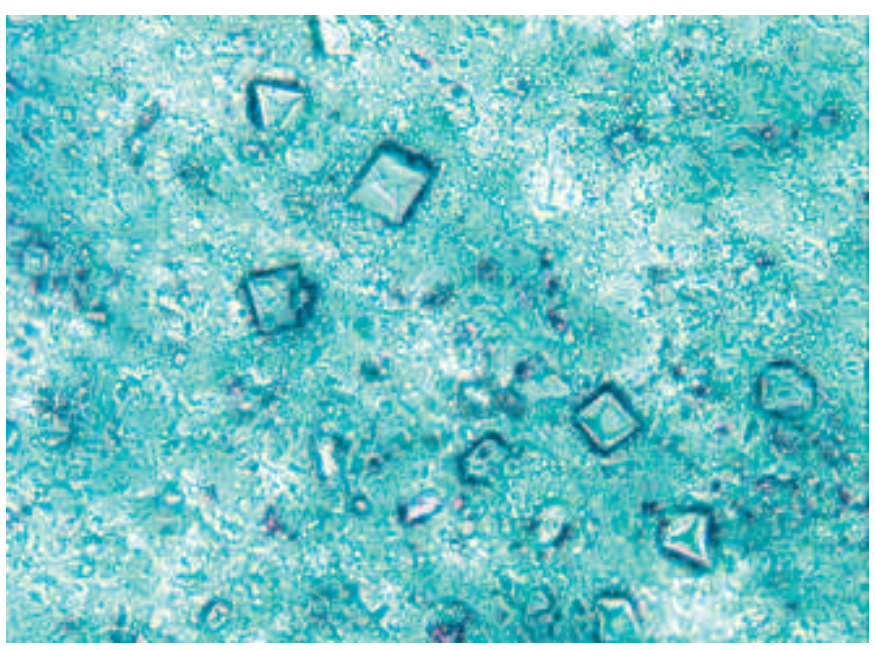

Figure $5 \quad A 330 \times 240 \mu \mathrm{m}$ picture of salt grains on first-stage stator vane pressure side along mean line

The technical roughness is influenced both by the size and by the shape of the salt crystals as well as by the distribution of salt crystals along the blade. The authors are fully aware of the difficulties involved when measuring technical roughness and the estimation of a technical roughness level from the twodimensional view given in Fig.5 will only give a ballpark estimate of the salt grains.

For all stages, the arithmetic mean diameter of the salt grains in the sample is considered a measure of the grain size, $\mathrm{k}$. The average distance between the salt crystals is calculated based on the number of crystals found in the sample. The associated equivalent sand roughness, $\mathrm{k}_{\mathrm{s}}$, is estimated based on the average distance between the salt grains and by comparing the ratio of grain size to grain spacing with the associated equivalent sand roughness for regularly arranged spheres $[18,19]$. The relative roughness is the ratio of equivalent sand roughness to the blade chord length. The results are given in Table 2. As expected, the largest relative roughness is found on the pressure side.

Table 2 Salt crystal grain size and distribution at mean line

\begin{tabular}{|c|c|c|c|c|}
\hline $\begin{array}{c}\text { Stator } \\
\text { vane }\end{array}$ & $\begin{array}{c}\text { Mean } \\
\text { grain } \\
\text { size, } \mathbf{k} \\
\text { (in } \boldsymbol{\mu} \mathbf{m})\end{array}$ & $\begin{array}{c}\text { Mean } \\
\text { grain } \\
\text { distance } \\
\text { (in } \boldsymbol{\mu} \mathbf{m})\end{array}$ & $\begin{array}{c}\text { Equivalent } \\
\text { sand } \\
\text { roughness, } \mathbf{k}_{\mathbf{s}} \\
\text { (in } \boldsymbol{\mu} \mathbf{m})\end{array}$ & $\begin{array}{c}\text { Relative } \\
\text { roughness, } \\
\mathbf{k}_{\mathbf{s}} / \mathbf{c h o r d}\end{array}$ \\
\hline $1 \mathrm{PS}$ & 22 & 88 & 25 & $11 \mathrm{E}-4$ \\
\hline $1 \mathrm{SS}$ & 14 & 88 & 10 & $4 \mathrm{E}-4$ \\
\hline $2 \mathrm{PS}$ & 16 & 62 & 20 & $11 \mathrm{E}-4$ \\
\hline $2 \mathrm{SS}$ & 8 & 25 & 15 & $8 \mathrm{E}-4$ \\
\hline $3 \mathrm{PS}$ & 15 & 65 & 15 & $10 \mathrm{E}-4$ \\
\hline $3 \mathrm{SS}$ & 5 & 40 & 2 & $0.6 \mathrm{E}-4$ \\
\hline
\end{tabular}

The small chord lengths of the GE J85-13 compressor make the engine sensitive to small grain sizes (in terms of relative roughness). Compared to the results given by Bammert and 
Woelk [20], the equivalent sand roughness levels given in Table 2 imply less roughness than from a surface of emery grade 320 .

\section{SIGNIFICANCE OF SALT DEPOSITS ON COMPRESSOR PERFORMANCE CHARACTERISTICS}

The effect of Reynolds number on compressor performance is well known for compressors in new and clean condition. The ASME test code on compressors [21] doesn't give any attention to testing in deteriorated conditions. A study of Reynolds number effects in centrifugal compressors shows how efficiency can be correlated to increases in the friction factor with increased surface roughness [22]. Some research exists on the effect of increased roughness in axial compressors: A study of profile loss due to surface roughness on NACA 65-12(06) profiles showed a $2 \%$ increase in the profile losses at a relative roughness $\left(\mathrm{k}_{\mathrm{s}} / \mathrm{chord}\right)$ of $3 \mathrm{E}-4$ and a $10 \%$ increase at $\mathrm{k}_{\mathrm{s}} /$ chord of 50E-4 [2]. Another study showed a $9 \%$ reduction in the static pressure ratio at a relative roughness, $\mathrm{k}_{\mathrm{s}} /$ chord of $10 \mathrm{E}-4$, but the static pressure ratio is a strong function of the volume flow and blade velocity [20]. Koch and Smith [23] quantified the effect of surface roughness on blade profile loss through a correlation for momentum thickness. Schäffler [19] gave additional insight into the boundary layer characterization of rough surfaces, although applied to new and clean surfaces.

The critical roughness Reynolds number, defined in Eq. 1 [19], is independent of the characteristic length of the compressor:

$$
\operatorname{Re}_{\text {critical }}=\frac{k_{s} V}{v}
$$

When the critical Reynolds number is above 90, the flow can be assumed hydrodynamically rough with turbulent attached flow (i.e., with the salt crystals protruding into the laminar sublayer). For these cases, the associated blade profile loss will depend solely on the surface roughness to chord level, and not on the chord Reynolds number [19].

Applying Eq. 1 to the GE J85-13, a critical Reynolds number of 90 implies a maximum equivalent sand roughness of $5 \mu \mathrm{m}$. Table 2 shows the salt crystals have equivalent sand roughness levels above $5 \mu \mathrm{m}$ for all stages except the suction side of stage three stator vanes. This implies that the blade loss, hence the efficiency, of the deteriorated engine will be dependent on the roughness level and not on the chord Reynolds number. The change in stage efficiency should therefore be possible to calculate based on the correlation for momentum thickness with surface roughness given by Koch and Smith [23].

Another aspect of the increased surface roughness is the change in deviation angle due to the thickening of the blade boundary layer. Mal'tsev and Shakov [24] found a correlation for changes in the deviation angle due to surface roughness based on tests of a helicopter engine after 1500 hours of flight. The relative roughness levels reported were in the range of $10.9 \mathrm{E}-3$ in the first stage to $0.7 \cdot 10 \mathrm{E}-3$ in the last stage and at
Reynolds numbers of 240,000. Typical Reynolds numbers in the GE J85-13 are 200,000 to 600,000 ; however, the relative roughness level given in Table 2 is only one tenth of the level reported by Mal'tsev and Shakov. Therefore, dhanges to the deviation angle due to deterioration are considered negligible for the salt-deteriorated GE J85-13.

\section{ENGINE PERFORMANCE DETERIORATION}

All overall engine performance parameters presented are corrected to ISO reference conditions [25]. Variations in humidity were not accounted for in the calculations. Data points measured at low speed settings were not included, because these include large unaccounted bleed flows.

\section{Initial salt deterioration trials}

Figure 6 shows the results from the initial salt-deterioration testing, where salt was injected in three separate tests without water wash in between. The figure show the total mass of salt ingested in the tests. The overall engine performance deterioration is shown for intake depression, which is defined as the difference between the total and static pressure in the bellmouth throat. The intake depression deteriorates rapidly and is outside of the measurement uncertainty tolerance even after $6 \mathrm{~g}$ salt ingestion. The intake depression was the most sensitive parameter to compressor deterioration and was found to be the best method for condition monitoring of the engine, because it is less dependent of the engine control mode.

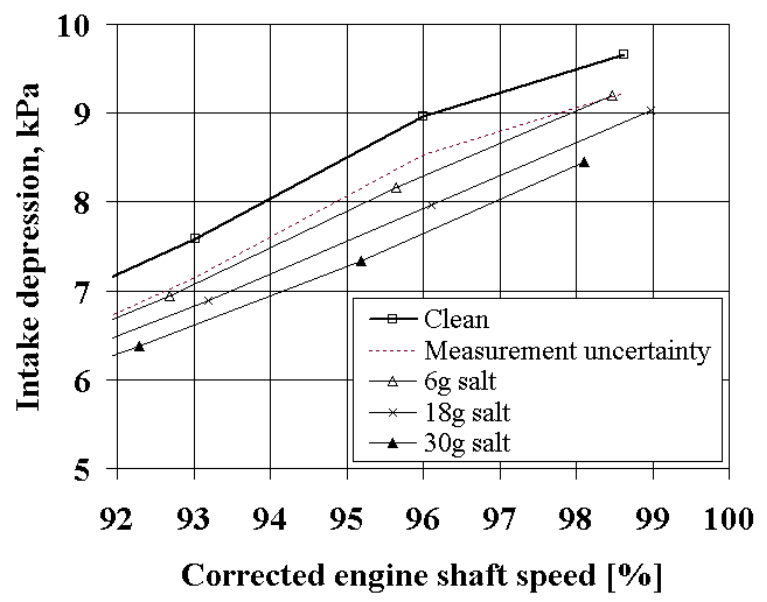

Figure 6 Deterioration of intake depression

\section{Overall engine performance deterioration}

The engine performance deterioration with $30 \mathrm{~g}$ of salt ingested is shown in Fig. 7-10. For simplicity in the presentation of data, only two representative cases are shown. These cases were recorded on the same day at identical compressor variable geometry and nozzle positions. Because the testing was done at ambient temperatures above the ISO reference condition, the $100 \%$ corrected speed setting was never reached. At these high 
ambient temperatures, the bleed-off-valves are fully closed above $95 \%$ corrected speed.

Figure 7 shows the engine performance deterioration in terms of changes on the compressor equilibrium operating line. Deterioration shifts the compressor operating line to a lower flow rate and a lower pressure ratio. This figure shows the static pressure at stage 5 (station 2.5) and at compressor discharge (station 3), and both curves show the same deterioration, indicating that the pressure deterioration was at the front end of the compressor. The results agree with those of Zaba [3] who found that front-stage fouling caused larger changes in the flow rate than in the pressure capability.

The surge line is not known for the engine; however, surge was not encountered at any time during the test.

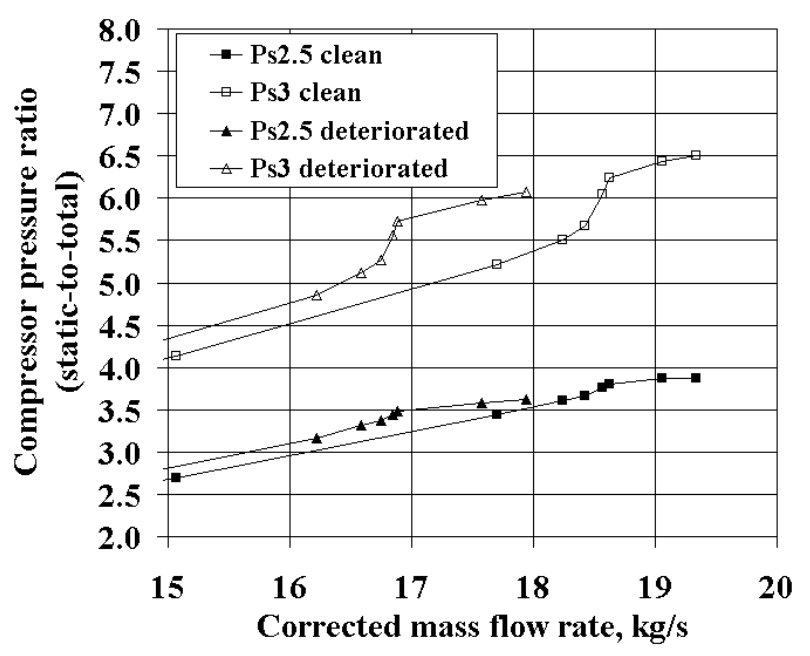

Figure 7 Effect of deterioration on compressor operating line

Figure 8 shows the change in exhaust gas temperature with thrust. The exhaust gas temperature is approximately nine percentage points higher for the deteriorated engine. The flattening of the deteriorated engine curve at the high end is due to exhaust gas temperature limitations in the engine control.

The variation in compressor isentropic efficiency with corrected engine shaft speed is shown in Fig. 9. This figure shows that deterioration reduces the isentropic efficiency by approximately three percentage points along the operating line. In addition, the deteriorated engine performance is shifted to a lower shaft speed, and the isentropic efficiency curves are flattened when the maximum exhaust gas temperature is reached.

The variation in compressor mass flow rate with engine shaft speed is shown in Fig. 10. This figure shows the significant reduction in air flow rate for the deteriorated engine. Again, the deteriorated engine performance is shifted to a lower shaft speed; however, the mass flow rate is only slightly affected by the exhaust gas temperature limitation. Mass flow rate is directly related to the intake depression which was found as the best parameter for engine condition monitoring in the initial salt deterioration trials.

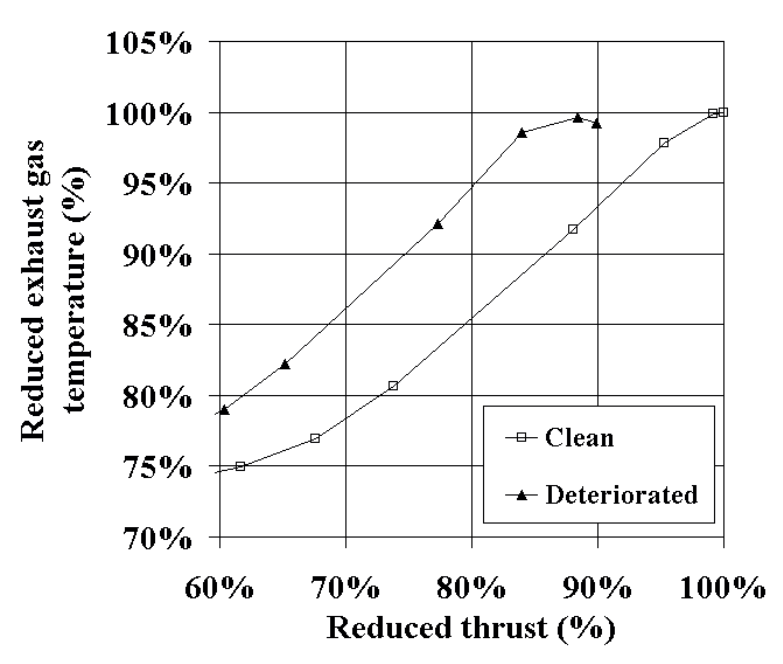

Figure 8 Change in exhaust gas temperature with thrust

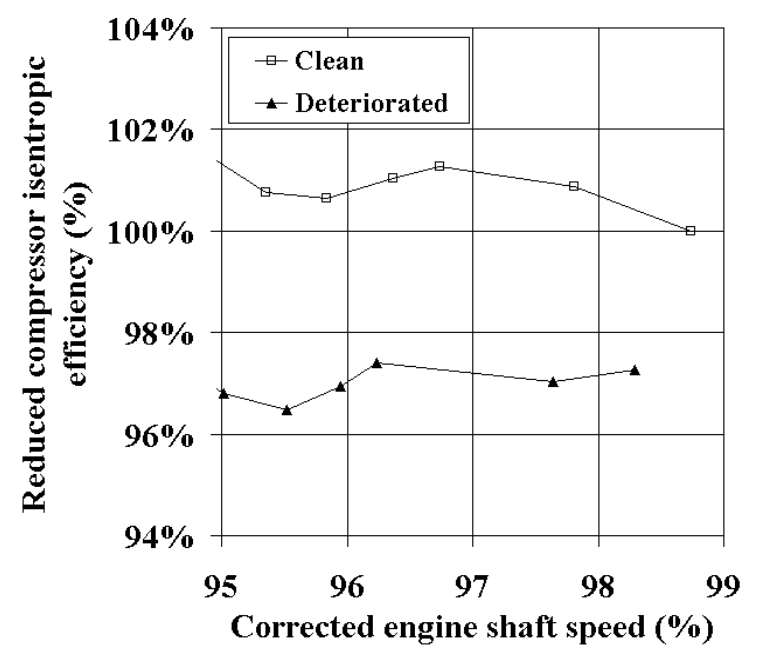

Figure 9 Deterioration of compressor isentropic efficiency

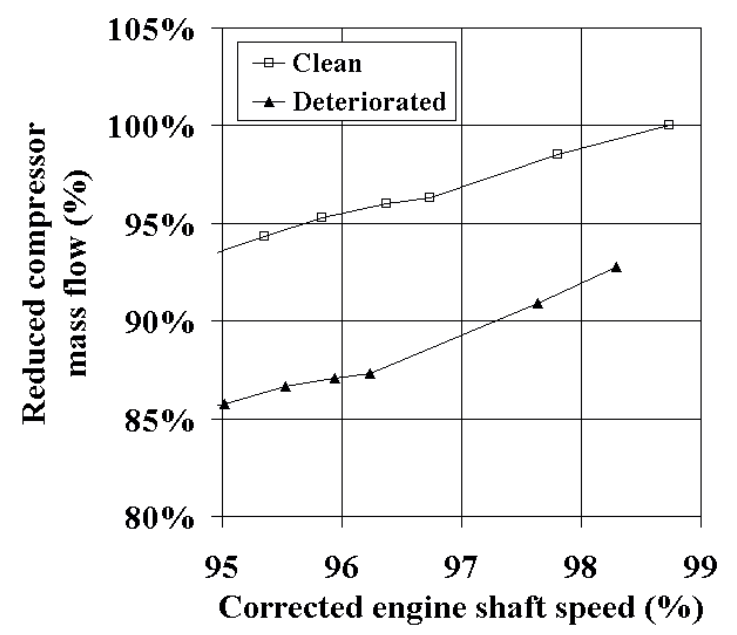

Figure 10 Deterioration of compressor mass flow 


\section{STAGE WORK COEFFICIENT DETERIORATION}

The compressor temperature measurements allow for a close look at the stage work coefficient during salt deterioration.

The presented test data are limited to engine operation above $95 \%$ engine shaft speed where the engine bleed-offvalves were closed and the IGV were fully open.

The following assumptions are made when analyzing the test data:

- The temperatures were measured at stages $1,3,4,6$, and 8 , and a linear temperature distribution was used for the remaining stages. The stage temperatures were measured in the stator; however, the measurements were assumed to be valid at the stator outlet plane.

- The temperature dependence of the specific heat at constant pressure and the ratio of specific heats are defined by a fifth-order polynomial correlation for dry air [27] and a seventh-order polynomial for water vapor [25]. These polynomial correlations fit original data within $0.1 \%$ at the temperature range applicable to the GE J85-13.

- Air is assumed to be a thermally perfect gas, but with humidity included in the calculation of $R, c_{p}$ and $\gamma$ as described in Appendix A. With an engine pressure ratio of $6.5: 1$, this implies a $0.3 \%$ error compared to the results using the Redlich-Kwong correlation for humid air mixtures [26] in the range of temperatures and pressures applicable to the GE J85-13 axial compressor.

- The axial velocity is assumed constant from rotor inlet to rotor outlet in a stage.

- The stage pressure rise is found from the measured polytropic efficiency.

- The stator deviation angle is assumed constant independent of incidence angle or corrected speed [9]. Increased deviation due to surface roughness is neglected as discussed above.

- The discharge coefficient of the bellmouth is assumed to be 0.98 .

- The pressure loss in the IGV is assumed negligible. For the data presented, the IGV are fully open and will not cause any turning of the flow.

- Deterioration is assumed to increase the sidewall boundary layers due to deposits on the first-stage annulus. The resulting decrease in effective flow area is modeled through a blockage factor defined as the ratio of true flow area to geometrical flow area. Assuming no deviation of the eightstage flow coefficient for the deteriorated engine compared to clean conditions, the deteriorated engine blockage factor was found to be 0.96 . The blockage factor is assumed constant for all stages.

- The equations used to calculate stage performance are given in Appendix B.

The test data are compared to the theoretical work coefficient based on the engine geometry and the stage work coefficient found in literature [7].
The theoretical work coefficient is defined from the Euler turbine equation, Eq. 2 [28],

$$
\Psi_{\text {theoretical }}^{T}=1-\Phi\left[\tan \left(\alpha_{1}\right)+\tan \left(\beta_{2}\right)\right]
$$

where $\alpha_{1}$ is the exit angle from the preceding stator and $\beta_{2}$ is the exit blade angle (relative) from the rotor.

The data published on stage work coefficient are calculated based on constant values for $\mathrm{c}_{\mathrm{p}}(1005 \mathrm{~J} / \mathrm{kgK})$ and $\gamma$ (1.4) [7], while in here, these gas properties are dependent on gas temperature and humidity. The difference will be largest in the aft stages where the gas temperatures are at the highest. Still, the published data gives a good indication of the GE J85-13 stage performance for a large range of flow coefficients.

Figures 11-14 show the change in the stage work coefficient with engine deterioration for stages $2-4$ and 6 . For stages 2-4, deterioration reduces both the stage work coefficient and the flow coefficient. This was expected for a degraded stage. For stage 6 the data for deteriorated engine and clean engine overlay each other. The same trend is found in all stages 5-8, indicating zero fouling in the aft stages. This agrees well with the observation of only minor traces of salt deposits in stage 5 and 6 and no salt deposits in stages 7 and 8 .

The measurements are in good agreement with the published data [7] for stages 2 to 4 . However, for stage 6, the measured stage work coefficient is higher than the published data. Because the current analysis is based on the difference between the clean and deteriorated condition, this deviation from expected stage work coefficient is of no consequence. The bellmouth discharge coefficient and the temperature recovery factor will influence on the stage work and flow coefficients. These factors are kept constant in the analysis.

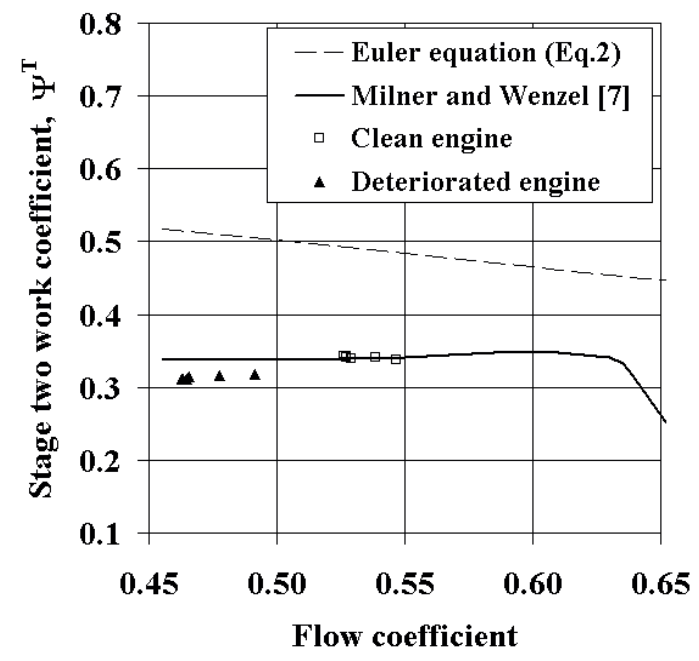

Figure 11 Stage two work coefficient 


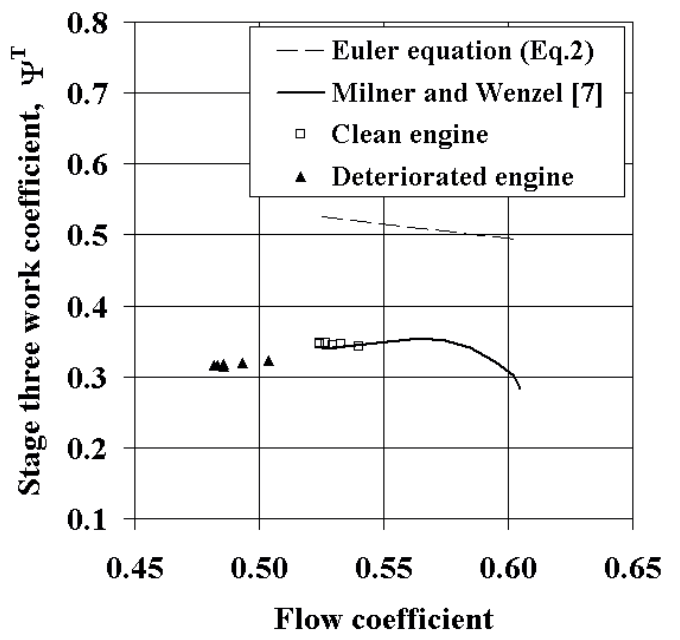

Figure 12 Stage three work coefficient

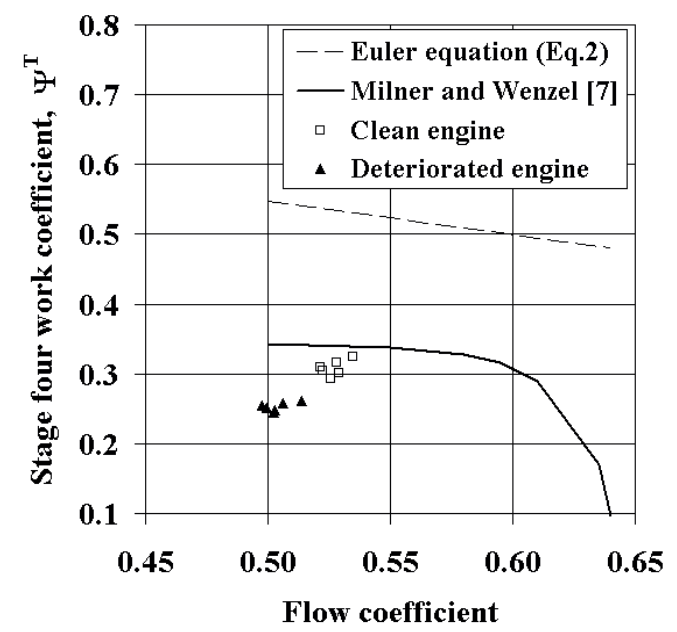

Figure 13 Stage four work coefficient

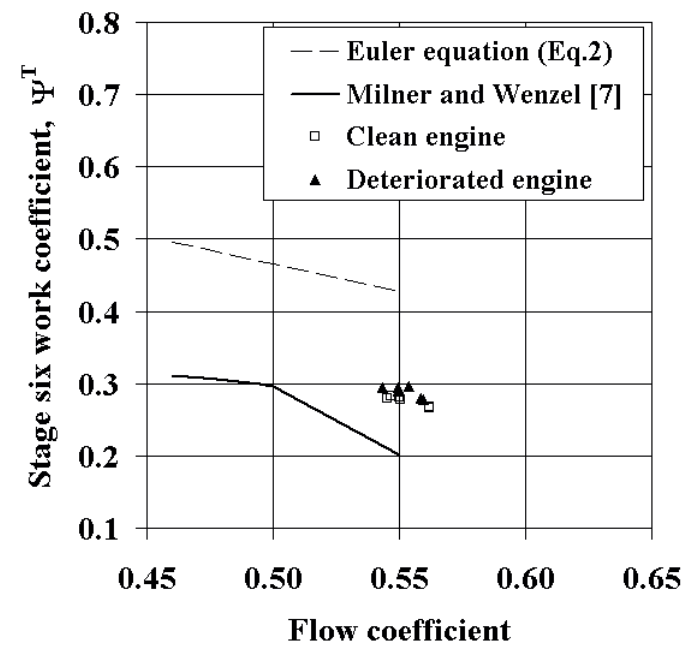

Figure 14 Stage six work coefficient

\section{CONCLUSIONS}

The test results presented in this paper show deteriorated performance of the GE $\mathbf{1 8 5}-13$ jet engine after accelerated saltdeterioration tests undertaken at the test facilities of the Royal Norwegian Air Force. Accelerated salt testing was found to be an effective method to systematically deteriorate gas turbine compressor performance.

Deposited matter in an engine will depend on the nature of the deposits (i.e., the material, the particle size and the adhesive capability of the deposits). With the present testing, the salt deposits were found mainly in the front stages of the compressor, and the stators were found to have more deposits than the rotor blades. The surface roughness levels and applicable Reynolds numbers were found to give added profile losses but no significant increases in the stator deviation angle.

The overall engine performance shows the difficulties involved in condition monitoring of deteriorated engines, because the deterioration causes a non-linear shift in the degraded performance. This hampers the comparison of deterioration trends based on the calculation of percentage deviation at constant corrected engine speed.

Intake depression was found to be the parameter most sensitive to compressor deterioration. In addition, intake depression was less influenced by the engine control mode.

The test data show good agreement with published data on incremental stage work and give valuable information of stageby-stage engine performance deterioration. The salt deterioration caused an increase in the sidewall boundary layers and significant deterioration in the stage characteristics of the first four stages.

This paper provides valuable information on stage performance deterioration used in the evaluation of test data from online water wash tests [5].

\section{ACKNOWLEDGMENTS}

The project has been supported by Statoil ASA, DresserRand Norwegian Operations and the Royal Norwegian Navy. The Royal Norwegian Air Force is acknowledged for allowing access to their test facilities and for allowing us to borrow a GE J85-13 for test purposes. Without the help of Mr. Hans K. Henriksen, a retired test-cell operator of the RNoAF this project would never have come to fruition.

\section{REFERENCES}

[1] Diakunchak, I.S., 1992, "Performance degradation in industrial gas turbines", ASME J. of Engineering for Gas Turbines and Power, 114, pp. 161-168.

[2] Kurz, R., and Brun, K., 2001, "Degradation in gas turbine systems," ASME J. of Engineering for Gas Turbines and Power, 123, pp.70-77.

[3] Zaba, T., 1980, "Losses in gas turbines due to deposits on the blading," Brown Boveri Review, 67, no. 12, pp 715-722. 
[4] Meher-Homji, C.B., Chaker, M.A., and Motiwala, H., 2001, "Gas turbine performance deterioration," Proceedings from the $30^{\text {th }}$ Turbomachinery Symposium, Texas A\&M, College Station,TX.

[5] Syverud, E., and Bakken, L.E., 2005, "On-line water wash test of GE J85-13", Proceedings of ASME Turbo Expo 2005, June 6-9, Reno-Tahoe, NV, GT2005-68702.

[6] Hager, R.D., 1977, "Analysis of internal flow of J85-13 multistage compres sor," NASA TM X-3513.

[7] Milner, E.J., and Wenzel, L.M., 1975, "Performance of a J85-13 compressor with clean and distorted inlet flow," NASA TM X-3304.

[8] Willoh, R.G., and Seldner, K., 1969, "Multistage compressor simulation applied to the prediction of axial flow instabilities," NASA TM X-1880.

[9] Tesch W.A., and Steenken, W.G., 1976, "Blade row dynamic digital compressor program: Volume 1 J85 clean inlet flow and parallel compressor models," NASA CR-134978.

[10] Saravanamuttoo, H.I.H. (ed.), 1990, "Recommended practices for measurement of gas path pressures and temperatures for performance assessment of aircraft turbine engines and components," AGARD Advisory Report AGARD AR-245.

[11] ASME PTC 22, 1997, "Performance test code on gas turbines."

[12] ASME PTC 19.1, 1998, "Test uncertainty."

[13] Caguiat, D.E., Zipkin, D.M., and Patterson, J.S., 2002, "Compressor fouling testing on Rolls Royce/Allison 501-K17 and General Electric LM 2500 gas turbine engines", Proceedings of ASME Turbo Expo 2002, June 3-6, Amsterdam, The Netherlands, GT2002-30262.

[14] ASTM Standard E 799-92, 1992, "Standard practice for determining data criteria and processing for liquid drop size analysis," ASTM International, West Conshohocken, PA.

[15] Caguiat, D.E., Connor, J., Duckless, E., DeCorso, R.J., 2004, "Inlet air salt concentration detection on U.S. Navy ship service gas turbine generator sets," Proceedings of ASME Turbo Expo 2004, June 14-16, Vienna, Austria, GT2004-53984.

[16] Tarabrin, W.P., Schurovsky, V.A., Bodrov, A.I., and Stalder, J-P., 1998, "Influence of axial compressor fouling on gas turbine unit performance based on different schemes and with different initial parameters", Proceedings of ASME Turbo Expo 1998, June 25, Stockholm, Sweden, ASME 98-GT416.

[17] http://www.struers.com

[18] Schlichting, H., 1979, Boundary-layer theory, Mc Graw-Hill Inc., New York, NY, $7^{\text {th }}$ edition.

[19] Schäffler, A., 1980, "Experimental and analytical investigation of the effects of Reynolds number and blade surface roughness on multistage axial flow compressors," ASME J. of Engineering for Power, 102, pp. 5-13.

[20] Bammert, K. and Woelk, G.U., 1979, “The influence of the blading surface roughness on the aerodynamic behavior and characteristic of an axial compressor," Proceedings of ASME Gas Turbine Conference 1979, San Diego, Ca, 79-GT-102.

[21] ASME PTC 10, 1997, “ASME performance test code on compressors and exhausters."

[22] ICAAMC, 1987, "Influence of the Reynolds Number on the Performance of Centrifugal Compressors," Proceedings of ASME Gas Turbine Conference, May 31-June 4, Anaheim, CA, 87-GT-10.

[23] Koch, C.C. and Smith, L.H., 1979, "Loss sources and magnitudes in axial-flow compressors," ASME J. of Engineering for Power, pp. 411-424.

[24] Mal'tsev, Yu.N., and Shakov, V.G., 1989, "Influence of roughness of deposits in compressor cascade on flow lag angle (english translation)," Izvestiya VUZ, Aviatsionnaya Tekhnika, 32, pp.80-82.

[25] Walsh, P.P., and Fletcher, P., 1998, Gas turbine performance, Blackwell Science Ltd, Oxford, UK,

[26] Aungier, R.H., 2003, "A fast, accurate real gas equation of state for fluid dynamic analysis applications," ASME J. of Fluids Engineering, 177, pp. 277-281.

[27] Keenan, J.H., Chao, J. and Kaye, J., 1983, Gas tables international version, SI Units, John Wiley and Sons, New York, NY, $2^{\text {nd }}$ edition.

[28] Saravanamuttoo, H.I.H., Rogers, G.F.C., and Cohen, H., 2001, Gas turbine theory," Prentice Hall, Pearson Education Ltd., Harlow, Essex, UK, $5^{\text {th }}$ edition.

\section{APPENDIX A GAS PROPERTIES FOR HUMID AIR}

Gas properties for humid air are calculated from the following correlations [25]:

$$
\begin{aligned}
& c_{p_{-} \text {mix }}=\text { war }_{\text {molar }} c_{p_{-} H_{2 O} O}+\left(1-\text { war }_{\text {molar }} c_{p_{-} \text {dryair }}\right) \\
& \gamma_{\text {mix }}=w a r_{\text {molar }} \gamma_{H_{2 O} O}+\left(1-w a r_{\text {molar }} \gamma_{\text {dryair }}\right) \\
& R_{\text {mix }}=\frac{R_{0}}{M W_{\text {mix }}} \\
& M W_{\text {mix }}=x_{H_{2} O} M W_{H_{2 O} O}+x_{\text {dryair }} M W_{\text {dryair }}
\end{aligned}
$$

where war $_{\text {molar }}=$ war $\frac{28.96}{18.015}$ 


\section{APPENDIX B: STAGE PERFORMANCE CALCULATIONS}

Consider a stage where the rotor inlet, rotor outlet and stator outlet are designated as station 1,2 and 3, respectively. The performance of a single stage is calculated using the following iterative sequence. The same sequence is used on all compressor stages.

1. The following parameters are known at the rotor inlet: $\mathrm{P}_{\mathrm{t} 1}$, $\mathrm{P}_{\mathrm{s} 1}, \mathrm{~T}_{\mathrm{t} 1}, \mathrm{~T}_{\mathrm{s} 1}, \mathrm{c}_{\mathrm{p} 1}, \gamma_{1}$ and $\mathrm{m}$.

2. From the principle of conservation of mass and the assumption of a thermally perfect gas, the following parameters are calculated at the rotor inlet:

$$
r_{1}=\frac{\mathrm{P}_{\mathrm{s} 1}}{\mathrm{R}_{\text {mix }} \mathrm{T}_{\mathrm{sl}}} \quad, \quad \mathrm{C}_{\mathrm{a} 1}=\frac{\dot{\mathrm{m}}}{\mathrm{r}_{1} \mathrm{~A}_{1}}
$$

3. The definition of total condition gives the absolute air velocity at the inlet:

$$
\mathrm{C}_{1}=\sqrt{2 \mathrm{c}_{\mathrm{p}_{-} \text {mix } 1}\left(\mathrm{~T}_{\mathrm{t} 1}-\mathrm{T}_{\mathrm{sl}}\right)}, \mathrm{C}_{\mathrm{wl}}=\sqrt{\mathrm{C}_{1}^{2}-\mathrm{C}_{\mathrm{al}}^{2}}
$$

4. The blade velocities at rotor inlet and outlet are given by the shaft rotation, where the radius, $r$, is the mean line radius for calculation of velocity diagrams and the tip radius for calculation of stage work coefficient.

$$
\mathrm{U}_{1}=2 \mathrm{pr}_{1} \frac{\mathrm{N}}{60} \quad, \quad \mathrm{U}_{2}=2 \mathrm{pr}_{2} \frac{\mathrm{N}}{60}
$$

5. To start the calculation loop, the static temperature at the stator outlet, $\mathrm{Ts}_{3}$, is given an initial value.

6. The total temperature is calculated from the temperature recovery factor and the measured temperature, $T_{m}$ :

$$
r=\frac{T_{t}-T_{m}}{T_{t}-T_{s}}
$$

7. All stage work is applied in the rotor row, hence the total temperature will not change across the stator row:

$$
\begin{aligned}
& \mathrm{C}_{\mathrm{w} 2}=\frac{\mathrm{c}_{\mathrm{p}_{\_} \text {mix } \_1}\left(\mathrm{~T}_{\mathrm{t} 2}-\mathrm{T}_{\mathrm{t} 1}\right)+\mathrm{C}_{\mathrm{w} 1} \mathrm{U}_{1}}{\mathrm{U}_{2}} \\
& \mathrm{C}_{2}=\sqrt{\mathrm{C}_{\mathrm{w} 2}^{2}+\mathrm{C}_{\mathrm{a} 2}^{2}} \\
& \mathrm{~T}_{\mathrm{s} 2}=\mathrm{T}_{\mathrm{t} 2}-\frac{\mathrm{C}_{2}^{2}}{2 \mathrm{c}_{\mathrm{p}_{\text {_mix }} \text { m }}}
\end{aligned}
$$

$$
\begin{aligned}
& \mathrm{r}_{2}=\frac{\dot{\mathrm{m}}}{\mathrm{C}_{\mathrm{a} 2} \mathrm{~A}_{2}} \\
& \mathrm{P}_{\mathrm{s} 2}=\mathrm{r}_{2} \mathrm{R}_{\text {mix }} \mathrm{T}_{\mathrm{s} 2} \\
& \mathrm{P}_{\mathrm{t} 2}=\mathrm{P}_{\mathrm{s} 2}\left(\frac{\mathrm{T}_{\mathrm{t} 2}}{\mathrm{~T}_{\mathrm{s} 2}}\right)^{\frac{\mathrm{g}_{\text {mix }}}{\mathrm{g}_{\text {mix }}-1}}
\end{aligned}
$$

9. The stage pressure rise is found from the measured polytropic efficiency and assumed constant in all stages:

$$
\begin{aligned}
& \mathrm{P}_{\mathrm{t} 3}=\mathrm{P}_{\mathrm{t} 1}\left(\frac{\mathrm{T}_{\mathrm{t} 3}}{\mathrm{~T}_{\mathrm{t} 1}}\right)^{\frac{h_{\text {poly }}}{g_{\text {mix }}-1}} \\
& \mathrm{P}_{\mathrm{s} 3}=\mathrm{P}_{\mathrm{t} 3}\left(\frac{\mathrm{T}_{\mathrm{s} 3}}{\mathrm{~T}_{\mathrm{t} 3}}\right)^{\frac{g_{\text {mix }}}{g_{\text {mix }}-1}} \\
& \mathrm{r}_{3}=\frac{\mathrm{P}_{\mathrm{s} 3}}{\mathrm{R}_{\mathrm{mix}} \mathrm{T}_{\mathrm{t} 3}}
\end{aligned}
$$

10. The stator exit velocity is found assuming zero deviation in the stator blade exit angle:

$$
\begin{aligned}
& \mathrm{C}_{\mathrm{a} 3}=\frac{\dot{\mathrm{m}}}{\mathrm{r}_{3} \mathrm{~A}_{3}} \\
& \mathrm{C}_{3}=\mathrm{C}_{\mathrm{a} 3} \cos \left(\mathrm{a}_{3}\right)
\end{aligned}
$$

11. Then, the value for $\mathrm{c}_{\mathrm{p}_{-} \text {mix }}$ at the stator outlet is updated based on $\mathrm{Ts}_{3}$, and a new value for static temperature at the stator outlet is calculated:

$$
\mathrm{T}_{\mathrm{s} 3}=\mathrm{T}_{\mathrm{t} 3}-\frac{\mathrm{C}_{3}^{2}}{2 \mathrm{c}_{\mathrm{p} \_ \text {mix_3 } 3}}
$$

12. The calculations are repeated from step 6 and on using the value for $\mathrm{Ts}_{3}$ found in step 11, and the whole sequence is repeated until $\mathrm{Ts}_{3}$ converges. 